\title{
Questioning design and method: exploring the value of action research in relation to $R \& D$ in primary care
}

\section{Julienne Meyer}

St Bartholomew School of Nursing and Midwifery, City University, London, UK

\begin{abstract}
The Mant Report supports the need to involve primary care practitioners and their patients in research and development. This paper questions why this key report, that recognized the need for involvement of health care staff in $R \& D$, did not identify the need for practitioner research methods in community practice. Next, it explores what is meant by practitioner-centred research and locates action research within this context. Drawing on 'critical realism' and 'subtle realism', the arguments for the use of action research in community research and development are explored. Caution is given to adopting extreme perspectives and, in preference to 'practitioner-centred research', practice-centred research is advocated. In conclusion, the paper suggests that the world of $R \& D$ is changing and that the time is right for influencing the uptake of alternative methods. It is suggested, given that $90 \%$ of contacts between the population and the NHS take place in primary care, it is vitally important that communitybased practitioners are well versed with these arguments in order to move forward the debate and bring it closer to a vision of research that places practitioners more centrally in the process of research.
\end{abstract}

Key words: action research; evidence-based practice; practice-centred research; practitioner researchers; practitioner-centred research; research and development

\section{Introduction}

The need to involve primary care practitioners and their patients is high on the government's national $\mathrm{R} \& \mathrm{D}$ agenda. However, there is a tendency to emphasize the use of more traditional research methods, at the expense of other methods that might be more useful to practice. This paper explores the value of action research in relation to research and development in primary care.

\section{R\&D in Primary Care}

In 1997, a working group of the Central Research and Development Committee set out its strategic

Address for correspondence: Professor Julienne Meyer, City University, St Bartholomew School of Nursing and Midwifery, Philpot Street, London E1 2EA, UK.

Email: j.meyer@city.ac.uk principles and objectives to guide the development of R\&D in primary care (NHSE, 1997). The working group was chaired by Professor David Mant and recognized that most research into the organization and delivery of primary care needs to be done in primary care, using a multidisciplinary approach. The report also noted that the appropriate involvement of primary care staff in R\&D is likely to increase the quality of clinical care in the NHS. However, it based its arguments on the fact that control patients in clinical trials fare better than patients outside trials; case survival is usually better in centres of excellence, and quality standards for clinical care often emerge from clinical research. The report appears to take a traditional view of research, implying that research experts should undertake research and that practitioners should later implement their findings. Within the report, the involvement of practitioners in research is about developing their capacity as experts to 
undertake research. It is not about tapping into their expert knowledge as practitioners, nor is it about blurring the interface of research, teaching and practice in order that a different form of knowledge can be developed that could be arguably more useful to practice. Thus, whilst recognizing the need for research capacity building in clinical practice, it does not recognize the unique contribution that practitioners can make when undertaking research. Instead, more emphasis is placed on the contribution of methodological expertise from the social sciences, epidemology, statistics and preclinical sciences, which is seen as being essential to high quality research. The expert practitioner is thus ignored and also, and as a consequence, the opportunity to develop a new type of knowledge arguably more useful to the practice.

\section{Practitioner-centred research}

Schon (1983) discusses the way in which society has become over reliant on the scientific method to generate findings that guide decision making in practice. He advocates the need for a new type of knowledge generated by alternative methods, namely practitioner-centred research. Drawing on the work of Ryle (1963) and Polanyi (1962), he argues that practitioners often find themselves working in situations of uncertainty, instability, uniqueness, and value conflict, which traditional forms of knowledge (e.g., scientific knowledge) are not always able to solve. He identifies that in the workaday life of professionals they are often dependent on a different type of knowledge (e.g., intuition and artistry of expert practice). In other words, he recognizes that practitioners have to draw from other sources of knowledge, apart from that which is written in text books, to sort out some of their clinical problems. He maintains that, through a process of reflection in action, practitioners learn to cope with uncertainty in practice by reflecting on what they are doing in a unique situation and restructuring their understanding as a result. Personal theories develop from these unique experiences and, over time, cluster into experiential theories as a result of repeated validation in practice. According to Schon, it is this tacit knowledge of expert practice that needs to be captured in order to better inform practitioners in their clinical decision making. He argues that the tacit knowledge of expert practice is needed, not only to make decisions when no scientific knowledge is available, but also to decide whether or not it is appropriate to apply scientific evidence to an individual case.

Even in the world of evidence-based healthcare that relies so heavily on scientific knowledge, the importance of tacit knowledge is recognized. For instance, Sackett et al. (1997) acknowledges the importance of professional judgement in applying scientifically derived research findings. He writes:

The practice of evidence-based medicine means integrating individual clinical expertise with the best available external evidence from systematic research. By clinical expertise, we mean proficiency and judgement that individual clinicians acquire through clinical experience and clinical practice.

Sackett et al. (1997: p. 2)

Professional judgement is seen to be a combination of different types of knowledge: scientific knowledge (that which is learnt from books 'knowing that') and tacit knowledge (that which can be learnt from experience - 'knowing how'). However, recognizing the importance of tacit knowledge in evidence-based practice is not enough, when the research methods for capturing such knowledge are not particularly supported or espoused in R\&D policies. As stated before, Schon argues that society places too much emphasis on the development of scientific knowledge and that there is a great need to form a better understanding of intuitive practice.

But how can tacit knowledge be tapped and better understood? Rolfe (1998) suggests that the answer lies in practitioner-centred research (PCR). Rolfe draws widely on research debates in education and defines PCR as 'systematic self-critical enquiry made public' (p. 75). It is concerned with practitioners examining themselves, their attitudes and their practice. It is essentially a reflexive approach in which the research has a direct impact on practice, which in turn modifies the research. This introspective, subjective approach contrasts with the detached, objective approach of the scientific method. It is a distinct type of research with a different philosophy, different aims, different methods and different outcomes. Rolfe (1998) suggests that there are a number of research methods that are ideally suited to PCR namely, single-case 
experimental research, reflective case-study research and reflexive action research.

\section{Single-case experimental research}

Single-case experimental research (SCER) is a method often used by psychotherapists and clinical psychologists, who sometimes find it hard to implement generalizable research findings within their individual clinical work. According to Rolfe, SCER is scientific and methodical, and involves the manipulation of one variable in order to observe its effects on a second variable. Individual patients are studied in relation to some form of intervention, whilst acting as their own control. Data are collected using quantitative methods that are designed to detect physiological changes, and/or changes in attitudes, knowledge and behaviour in individual patients. It is ideally suited to those working in the community, who often work on a one-to-one basis with individual patients and would find it hard to control the wide range of variables necessary to conducting large-scale experimental research with a larger number of participants.

\section{Reflective case-study research}

According to Rolfe (1998), reflective case-study research derives from clinical psychology, sociology and anthropology. Case-study research is characterized by studying one or more 'cases' (individuals, groups, organizations, issues or events), using a variety of different data collection methods. Cases are studied in their real-life context and can be used to illuminate issues or to build or test theory. The practitioner researcher reflectively explores their own practice, combining data from interviews, document analysis and observations. Again the small-scale nature of this work makes it an easier research choice for community staff to undertake. With illuminative case studies, generalization depends largely on there being contextual similarity between two settings and this is usually referred to as transferability (Guba and Lincoln, 1989) or fittingness (Koch, 1994). The case study is written up in its rich contextual detail and the reader is invited to judge the relevance of the findings to themselves in their own practice situation. The truths contained in a successful report are thus assumed by shock of recognition (Simons, 1971). Other case studies, designed to build or test theory, use deviant-case analysis and the constant comparative method to make theoreti- cal generalizations to other contexts and patient groups (Silverman, 1993).

\section{Reflexive action research}

Finally for practitioner researchers, whose aim is to integrate research into their everyday practice, a reflexive action research approach is required (Rolfe, 1998).

Rolfe describes reflexive action research as: 'a problem-centred, cyclical research methodology in which the practitioner-researcher explores and implements new ways of resolving problematical issues for her own practice' (Rolfe, 1998: p. 179).

Research is carried out by the practitioner into their own practice, with a view to bringing about direct improvement, thus contributing to their own personal knowledge and theory. With this approach, practitioners identify problems, seek solutions and monitor the process and outcomes of change in the context of their everyday work. However the focus is on the individual practitioner and the learning that takes place at this level. Practitioner-centred research is thus well placed to explore the meaning of tacit knowledge in expert practice. However, the dominance of the scientific method in western society makes its acceptance problematic. Protagonists need to be able to explain its philosophical underpinnings, in order to persuade others of its usefulness. To do this, Winter and Munn-Giddings (2001) draw on 'critical realism' to explain the value of action research, in particular.

\section{Critical realism}

The emergence of 'critical realism' as a legitimate philosophical underpinning for research can be seen as a response to a growing awareness about the limitations of alternative paradigms (Carr and Kemmis, 1986; Susman and Evered, 1978). In essence, quantitative approaches (based on positivism) are thought inappropriate due to problems treating human beings working in complex organizations as though they behave like test tubes in a laboratory. Whereas qualitative approaches (based on interpretivism) are found limiting by their lack of concern about changing practice and by their over reliance on the researcher as expert, instead of the practitioner.

Winter and Munn-Giddings (2001) highlight eight points in linking action research to critical 
realism (see Table 1). First, critical realism asserts that the complexity of social situations is such that no general laws can prescribe action for particular instances. Thus there is a need for professional judgement in the implementation of research findings in clinical practice and a need to be contextually specific in reporting research. By describing action research studies in their rich contextual detail, attempts to implement scientifically derived, evidence-based practice can be explored. It is not

Table 1 Action research and critical realism

1) Critical realism asserts that the complexity of social situations is such that no general laws can prescribe action for particular instances. Hence the value of indeed the necessity for - the contextually specific inquiries of action research, as narratives of our attempts to interpret the here-and-now implications of bodies of generalized knowledge.

2) Critical realism asserts that social inquiry is always part of the social world it describes. (Hence the action research principle of reflexivity, which emphasizes that the process of research is always also a topic for inquiry.) It therefore follows that social inquiry does not have an external 'platform' from which researchers can conduct 'objective' observations of 'those being researched'. Hence the significance of the action research ideal of research as participatory, collaborative process, in which participants are encouraged to take a creative part in negotiating the focus and conceptual framework for interpreting data.

3) Critical realism asserts that any current state of knowledge is fallible, incomplete and influenced by historical factors such as ideologies, values and interests of particular groups. Hence the important emphasis, within action research, that 'analysis' (of data, events, situations) is always a mutual process of critical, evaluative reflection.

4) Critical realism asserts that the purpose of social inquiry is to understand situations in such a way that we are able to bring about change. This, of course, is explicitly one of the central, defining principles of action research.

5) Critical realism asserts that social activity does not simply reproduce situations; it transforms them: there is always a 'space of freedom' between, on the one hand, initial conditions and contextual constraints and, on the other hand, what we actually, finally do. This is what makes it realistic to propose that inquiry can bring about change (point 4). If, in principle, structures of power do not wholly or finally determine individual action, there are theoretical grounds for optimism on the part of action research participants in their pursuit of change in particular contexts.
Table 1 Continued

6) Critical realism asserts that inquiry is a process of 'work'; our understanding develops through a continuous process of 'causal exchange' with objective reality. This is the 'dialectic' whereby knowledge develops through an interaction between creative conjecture and the 'test' of experience. For academic social scientists this is problematic: its methods (surveys, controlled experiments, ethnographic observation, etc.) always interpose a predefined conceptual framework between any hypothesis and the experiential work in which (supposedly) it is tested, so that the 'reality' of any 'findings' is always in question. For action research, however, the dialectic between conceptualization and reality is considerably clearer. In seeking practical change action research necessarily places a primary focus on the 'real world' of participants' experience. Action research includes the experiential realities of professional practices, clients' situations, institutional structures and social relationships, as essential elements of the dialectic between action and reflection which constitutes the inquiry process.

7) Critical realism asserts that social inquiry seeks to identify objective 'structures' and 'forces' underlying subjective experiences. For academic social science this is problematic, because researchers' conceptual frameworks for interpreting a situation are not necessarily derived from the experiences of those in the situation to be interpreted. For action research, however, the objective structures and forces at work in the situation are identified as the basic shape of the inquiry, i.e., as the set of 'stakeholders' who need to be involved as participants in the research. The form of an action research inquiry is thus directly derived from the 'objective structure' of the situation in which it takes place, since it consists of dialogue and negotiation between the potentially conflicting forces which make up the situation, as an attempt to identify and resolve contradictions among a variety of interest groups, both at the level of theory ('ideology') and practice.

8) Critical realism asserts that social inquiry is not value neutral; it must assume and seek to enhance the values of justice, rationality and truth. Its purpose is to increase the autonomy of citizens, to enable them to redescribe the experience in terms which they themselves have tried to create, and to recreate that experience in the form of a collectively desired state of affairs. For academic social science such values normally remain a set of criteria for evaluating the purpose and impact of an inquiry. Action research, however, seeks also to embody these values in its processes, i.e., in the attempt (never fully successful, of course) to carry out inquiry through suspending hierarchical role relationships in favour of a free and collaborative interchange of critical analysis among all interested parties.

Reproduced with permission from Winter and MunnGiddings, 2001. 
assumed that evidence-based practice is appropriate for all people, but by exploring the narratives of attempts to change practice, more can be learnt about those situations where the evidence appears inappropriate. In the community this is particularly relevant given that findings are often generated in secondary care settings and therefore may not be appropriate to primary care contexts.

Second, Winter and Munn-Giddings argue that critical realism asserts that social enquiry is always part of the social world it describes. In other words, knowledge is socially constructed and, as such, researchers need to be explicit about their own assumptions about what constitutes knowledge and explore the meanings of others. This is done through reflexivity, which emphasizes the process of research as part of the topic of enquiry. Instead of the expert researcher standing back and objectively observing practice, participants in action research are actively encouraged to collaborate not only in the change process, but also the process of research. This allows them to take a creative approach to the interpretation of data and for their expert intuitive knowledge of practice to be explored. Given that only limited scientific research has been undertaken in primary care settings, it is likely that community practitioners have had to rely heavily on intuition over time. Potentially, therefore, there is a wealth of untapped tacit knowledge to be explored.

Next, critical realism asserts that any current state of knowledge is fallible, incomplete and influenced by historical factors such as ideologies, values and interests of particular groups. According to Winter and Munn-Giddings (2001), this is why the mutual process of critical, evaluative reflection is so important in action research. We cannot assume that scientifically derived findings are useful to practice. This can be seen in relation to asthma treatment. Medical sociologists (Green and Britten, 1998) suggest that whilst there is consensus over evidence-based practice in the treatment of asthma (British Thoracic Society, 1993), questions remain about general practitioners' use of clinical guidelines and patients' use of prescribed medication (Audit Commission, 1996). Action research allows a range of stakeholder perspectives to be considered, which might explore whether users are concordant with recommended treatment regimes. It also allows the barriers to implementing evidence-based practice to be uncovered, as they naturally occur in the field. Green and Britten (1998) argue that these are the advantages of qualitative methods. However, qualitative methods are often reliant on selfreported perceptions, whilst action research allows not only for observation of practice, but also, critical debate and evaluative discussion with participants in the field.

Winter and Munn-Giddings' fourth issue concerns the fact that critical realism asserts that the purpose of social enquiry is to understand situations in such a way that we are able to bring about change. Too often research is undertaken by academics without any consideration for changing practice. Alongside its participatory character and democratic impulse, a key feature of action research is its simultaneous contribution to social science and social change (Carr and Kemmis, 1986). Change is a natural feature of action research and, even if the findings do not influence practice more widely, at least those who have participated in the study will have learnt from the collaborative experience of trying to do so.

Fifth, critical realism asserts that social activity does not simply reproduce situations; it transforms them. Within action research, the democratic process of engaging with all stakeholders in determining the nature of change and the process of research can be very empowering, even within hierarchical contexts such as the National Health Service. Unlike other forms of research, which use a 'smash-and-grab' approach, action research feeds back findings to participants for critical comment. This in itself can have a powerful influence and change the dynamics of professional practice. Action research is often used to cross between traditional boundaries (e.g., users and professionals, hospital and community, health and social care). By sharing perspectives across these boundaries, situations are transformed to a greater or lesser extent.

Sixth, Winter and Munn-Giddings claim that critical realism asserts that enquiry is a process of 'work'. They argue that knowledge develops through interaction between creative conjecture and the test of experience. More traditional forms of research (quantitative and qualitative) do not allow for this 'dialectic'. Findings are disseminated and it is assumed, despite the contrary evidence (Walshe etal., 1995), that practitioners will implement them willingly in practice. However, in action research, the 'dialectic' between action and 
reflection allows ideas to be explored and tested as part of the process of research. It is one of the few methods that take account of the ' $D$ ' in 'R\&D'. As such, it could have an important role to play in future health service research.

According to Winter and Munn-Giddings (2001), critical realism also asserts that social enquiry seeks to identify objective 'structures' and 'forces' underlying 'subjective' experiences. In action research by gathering a wide range of stakeholder perspectives, the potentially conflicting forces in any embedded situation can be explored through dialogue and negotiation. Action research thus has the power and potential to resolve contradictions. Without engaging with key stakeholders in this way, other forms of research run the risk of inappropriately objectifying a situation without real understanding. Too often, research is undertaken by academics, who do not have a working knowledge of practice. Without dialogue with practitioners, the researcher's assumptions cannot be challenged and this risks findings being inappropriately derived and of limited use to practitioners.

Finally, critical realism asserts that social inquiry is not value neutral and must seek to enhance the values of justice, rationality and truth. The democratic principles of action research ensure that equal voice is given to all participants and that through free, collaborative and critical exchange of ideas participants are given the opportunity to influence their future practice. Other forms of research do not always address a range of perspectives and do not always share the findings with those who have generated them. This keeps the power base with the funder, who may have ulterior motives not to act upon them.

\section{The need for subtle realism}

Whilst critical realism, justifies the use of action research it should be remembered that there are many different forms of action research. Hart and Bond (1995) describe a typology of action research, which includes four different types (experimental, organizational, professionalizing and empowering) in relation to seven different dimensions, along a continuum. Rolfe's (1998) choice of practitioner-centred 'reflexive action research' is at the empowering end of the continuum, but perhaps it is unrealistic to expect prac- titioners to engage so reflexively in their day-today work. By focusing so much on the individual and the development of personal learning, Rolfe's approach might be rejected as being associated with a commitment to ontological idealism and epistemological relativism. Idealists reject the notion of 'objectivity'. For them, it is possible for many, even contradictory, truths to coexist (Guba and Lincoln, 1989) and thus are often accused of relativism. Critics (e.g., Murphy, 2001), argue that with the idealist approach all that researchers can hope to do is to spawn multiple, incommensurable, potentially contradictory versions of the world, on the basis of the same research experience, and Murphy (2001) argues that it is difficult to justify the expenditure of public money on such research. Instead, drawing on Hammersley, M. (1992) What's Wrong with Ethnography? London: Routledge, she argues the need for 'subtle realism', where reality is said to exist independently of the researcher's claims about it. Subtle realists do not claim to reproduce reality but seek to represent it, recognizing that phenomena can be represented from different perspectives. In so doing, this allows their work to potentially guide others and, therefore, be of more value to policy makers. Whilst Rolfe's (1998) vision that all nurses should engage in practitioner-centred research in order to understand better the artistry of practice is laudable, it is doubtful that this will ever be achieved. It is an extremist approach that will alienate many.

\section{Beware of extremes}

Living in a pluralist society gives freedom to embrace a range of perspectives. However, one should be cautious about working with extreme perspectives, as they may have only limited influence. Whilst recognizing the value of Rolfe's work, one has to be reminded of the purpose of research, namely to assist others to see the world in such a way that they may wish to base their practice on it. It is important to work within the cultures and discourses found in practice (Somekh, 1994). This can best be illustrated by an action research study, funded by the Department of Health (Meyer et al., 1999), to explore the involvement of older users and carers in the assessment of their individual continuing health and social care needs. This study tracked patients across the inter- 
face of primary and secondary care and findings were fed back to user and carer groups and uniand multiprofessional groups with a view to changing practice. A key finding to emerge from this study was the way in which professionals were more inclined to engage when they heard stories, in the patients' own words (anecdotes), rather than to listen to the results of the more rigorous thematic analysis. In response to this, the researchers obtained further funding from the Department of Health to explore more innovative ways of disseminating findings. Going back to the data, stories were reconstructed and were then centrally fed into the Emap Healthcare Open Learning Diploma/Degree programme in Care for Older People. As core material in this programme, it is hoped that professionals will better hear the voices of older people. This way, the study can be seen to be working within the cultures and discourses of practice. Not only do researchers need to be able to relate to policy makers, but in addition they also need to be able to communicate with those in practice. By focusing too much on relating to practitioners, Rolfe's extreme position is in danger of being ignored. It could be argued that at this stage of development, instead of practitioner-centred research, perhaps a more realistic and appropriate goal for community research and development might be practice-centred research.

\section{Practice-centred research}

Practice-centred research incorporates many of the philosophical underpinnings of practitioner-centred research, but does not rely on individual practitioners focusing so much on themselves and their own intuitive knowledge. The important feature here is that research should take place in practice and focus on understanding change as it naturally occurs in the field. Practice-centred research can be undertaken by practitioners in the course of their everyday work or outside facilitators can assist practitioners to tap into their expert knowledge to help design appropriate studies and, where possible, to engage in research with a view to improving practice. This sort of research would not focus only on the individual and their personal learning, but would involve other stakeholders (practitioners, managers, users and their informal carers) and would contribute to a wider body of knowledge by setting findings in the context of previous research. The researcher's account would be clearly visible within the accounts of other participants and conclusions drawn to help guide future practice. However, it would be recognized that this account might be inaccurate and so the reader would always be invited to judge the relevance of the findings to themselves in their own situation.

It could be argued that outside facilitators of practice-centred research should be practitioners, who have an in-depth understanding of the contexts in which they work. This clinical credibility would allow them to more easily become associated as insiders, by demonstrating a greater sensitivity to practice issues. This closeness would help the researcher to capture better the realities of the practice world, as it naturally unfolds. Reed and Proctor (1995) support the need for research to be undertaken by practitioners. They suggest that practitioner researchers have particular knowledge and understanding which profoundly affects the way in which research is conducted. They do not claim it to be better, just different and not to be ignored.

\section{Practice-centred research in primary health care}

In primary care there are some excellent examples of practice-centred research, undertaken by practitioner researchers. For instance, the Teamcare Valleys (TCV) project (Bryar and Bytheway, 1996) included a number of studies undertaken by practitioners in their everyday work. This project was a multifaceted primary health care (PHC) development project initiated and funded by the Welsh Office for 3 years with the remit to help improve primary health care in the South Wales Valleys. TCV arose from a belief that best practice needed to be underpinned by research. There was a concern that there were vast areas of PHC practice for which research evidence was lacking and therefore a desire to develop practitioners with research knowledge and skills to undertake research. The project was staffed by a team of people, recruited largely from general practice, district nursing, health visiting, community psychiatric nursing, health promotion and midwifery, who were employed either as long-term (i.e., 3 years) clinical fellows (LTCF), or as short-term clinical fellows (STCF) for one or more sessions a week for a period from a few months up 
to 2 years. The studies explored a range of topics including some in management, audit, education, community needs and teamwork. Interestingly, the STCFs were found to be more successful than the LTCFs (Bryar, 1999). Whilst all clinical fellows completed their projects, developed new skills and felt increased self-confidence, the STCFs were better able to facilitate rapid implementation of research findings. This was thought to be due to their insider positions within the contexts in which they worked. The LTCFs were greatly affected by the lack of clarity in their roles and the different expectations held of them both within TCV and in the wider environment. The majority of the LTCFs adopted an academic model to structure their work, which was for some more compatible with their aspirations on joining TCV. For others, although they adopted this model, it was in conflict with the practice development goals they had had at the beginning of TCV. The study concludes that organizations supporting practitioner research need to consider the purposes and cohesion of the internal environment, expectations and requirements of the external environment and personal expectations of the practitioners. Perhaps the best way forward here is through the use of action research.

\section{Practice development through action research}

At City University, a programme of practice development through action research has grown rapidly over a five-year period. Currently work is being undertaken in nine NHS Trusts and focuses mainly on care for older people with the subthemes of user and carer involvement and interprofessional working. It seeks to blur the interface of research, education and practice and is another example of practice-centred research. One study (CELEC Action Research Project: Care for Older People) involves seven different trusts cross-fertilizing ideas through the appointment of seven Lead R\&D Nurses. These nurses are working to the agenda of the trust to implement evidence-based practice in line with the National Service Framework for Older People. The projects are wide ranging and include: care for older people in the acute phase of illness (two sites), the introduction of an integrated care pathway on managing continence in the community, the development of mental health skills in general nurses working with older people and the develop- ment of mental health nurses to work with those older patients who have enduring mental health problems, person-centred care in a continuing care setting and working with staff to develop their rehabilitation skills. Completed action research projects include work integrating health and social care at various levels within organizations. Work has been undertaken across a health authority (development of protocols for the transition of care from hospital to nursing homes (Cotter et al., in progress)), across a general medical directorate (evaluation of the care co-ordinator role (Bridges and Meyer, 2001a)), within an accident and emergency department (service delivery and organization of care (Meyer and Bridges, 1998)) and within a rehabilitation ward for older people (addressing psychosocial needs (Bridges and Meyer, 2001b)). The work has often been refunded by participants which demonstrates its local value, but in addition, it has been recognized at the national and international level through publication in a wide range of peer-reviewed and nonpeer-reviewed journals. The strength of this work lies in the researchers all being practitioners, who are all based in local NHS Trusts. The researchers' skills lie in being able to communicate across traditional boundaries, sharing perspectives and shedding light on the issues and problems of trying to improve practice. The outcomes of action research can include models of good practice or reports of some of the challenges faced in trying to put policy into practice. For this sort of work, research skills alone are not enough. Good interpersonal skills are needed and arguably a related professional background to gain acceptance in the practice setting.

\section{Mant: missing the point}

Clearly both practitioner-centred research and practice-centred research are forms of research that can be undertaken by practitioner researchers. Indeed it is argued that this is the preferred model. However, according to Bryar (1999), there are few research policy documents that recognize the importance of the practitioner-researcher role. Although the Mant Report highlights the need to develop the research and development skills of practitioners, it does not address the potential contribution that practitioner researchers could make to research and development. Until models of 
research are adopted that give the control back to practitioners, it is doubtful that research will ever truly influence practice. Practitioners need to be encouraged to critically analyse their day-to-day work and value the knowledge that can be derived from a better understanding of expert practice. In addition, they need to be able to influence the research designs of others in order that more appropriate research is undertaken that more directly meets their needs in practice. Where possible, practitioners need to be involved in the process of research to develop their own skills and to be engaged in the sort of research that is going to solve practice problems and develop services. Action research has much to offer here. Its focus on change ensures that development issues, which are frequently ignored, are centrally addressed. By crossing traditional boundaries (hospital and community, health and social care, education and practice, interprofessional boundaries, user and carer perspectives) much can be learnt from the experience of others, whilst attempting to improve care. Whilst there will always be a place for scientifically generated knowledge, it should not be revered to the exclusion of other bodies of knowledge such as practice-centred knowledge.

\section{Time is right}

The time is right to engage in a methodological discussion and to question design and method. However, we need to move beyond a discussion of the difference between qualitative and quantitative paradigms and start to grapple with the importance of undertaking new forms of research. This is not a debate going on in isolation. Several years ago, it was suggested that the historical development of nursing research was following a similar pattern of development to that in mainstream education (Meyer, 1993). Having gone through specific decades when positivist and interpretivist approaches were popular, both disciplines came to value the practitioner as researcher. This pattern fits in with a broader trend that marks a distinct shift towards replacing or reforming established research institutions, disciplines, practices and policies. Focusing on research and development in science and technology, Gibbons et al., (1994) argue the need for a new mode of research that emphasizes reflexivity, transdisciplinarity and heterogeneity.
They argue that research should not be set within a particular disciplinary framework, but should be undertaken in the context of its application and involve the close interaction of many actors throughout the process of knowledge production. They argue that research should be carried out in nonhierarchical, heterogeneously organized forms, which are essentially transient. They advocate closer links between research and development and suggest that the traditional means of disseminating findings (e.g., peer-reviewed journals) will become increasingly outmoded, given the rate of change in society. Action research fits into this new mode of knowledge production and is even specified in relation to a desire to link teaching and professional practice (Gibbons et al., 1994: p. 80).

But where is R\&D policy in relation to this vision? Only a few years ago, there appeared to be a mismatch (Meyer and Batehup, 1997). However, more recently, national $\mathrm{R} \& \mathrm{D}$ funding bodies (e.g., SDO R\&D programme) expressed an interest in new methodologies, including action research, to study the organization and delivery of health care services (Fullup et al., 2001). There have even been attempts, funded by the HTA R\&D programme to systematically review action research and establish criteria for judging its quality (Waterman et al., 2001). There is clear recognition of the need to widen perspectives. Wood, M. and Ferlie, E. (2000) The Role of the Investigator in the Translation of NHS R\&D Findings into Practice. Final Report. NHS Executive London, R\&D Programme, December, suggest that legitimation for research no longer seems to flow through disciplinary consensus, correspondence and expertise, but is practically constructed through technical and social interplay, interaction and (sometimes commercial) engagement.

\section{Conclusion}

Today's symposium is a prime example of social interplay, interaction and engagement. Recorded in the annals of the journal Primary Health Care Research and Development, it has the potential to influence a wide range of people nationally and internationally. As professionals caught up in this debate, we need to be clear about our own views and the rationale behind them. For me, practice-centred research and, action research in particular, offers the opportunity to blur the boundaries between research, 
practice and education. It is nonelitist and values the knowledge of those working in day-to-day practice. Its democratic impulse allows a range of perspectives to be incorporated (users, carers, professionals, managers, policy-makers) and through the research process offers opportunities for learning and improving care. As a nurse, it would be hard to do the sort of research which may or may not influence practice. At least with action research, even if our attempts to change practice prove difficult, the lessons learnt from trying can be invaluable to others. Practitioners do not want the sort of research that has been so controlled and sanitized that it no longer relates to practice. Nor do they want experts, divorced from practice, to interpret their world for them. Instead they have a right to be involved in both research and development and to have the opportunity to shape a better understanding of their everyday work.

\section{References}

Audit Commission. 1996: What the doctor ordered: a study of GP fundholders in England and Wales. London: HMSO.

Bridges, J. and Meyer, J. 2001a: The interprofessional care coordinator project. London: City University.

Bridges, J. and Meyer, J. 2001b: Improving the rehabilitation care of older people. London: City University.

Bryar, R. 1999: The transition of practitioner to practitioner researcher in primary care. Unpublished $\mathrm{PhD}$ thesis, University of Wales College of Medicine, Cardiff.

Bryar, R. and Bytheway, B. (Eds) 1996: Changing primary health care. The Teamcare Valleys experience. Oxford: Blackwell Science.

British Thoracic Society. 1993: Guidelines for the management of asthma: a summary. British Medical Journal 306, 776-782.

Carr, W. and Kemmis, S. 1986: Becoming critical: education, knowledge and action. London: The Falmer Press.

Cotter, A., McCormick, K. and Meyer, J. (in progress) The hospital discharge project. London: City University.

Fullup, N., Allen, P., Clarke, A. and Black, N. 2001: Studying the organisation and delivery of health services. London: Routledge.

Gibbons, M., Limoges, C., Nowotny, H., Schwartzman, S., Scott, P. and Trow, M. 1994: The new production of knowledge: The dynamics of science and research in contemporary societies. London: Sage.

Green, J. and Britten, N. 1998: Qualitative research and evidence based medicine. British Medical Journal 316, 1230-2.

Guba, E.G. and Lincoln, Y. S. 1989: Fourth generation evaluation. Newbury Park: Sage.

Hammersley, M. 1992: What's Wrong with Ethnography? London: Routledge.

Hart, E. and Bond, M. 1995: Action research for health and social care: a guide to practice. Milton Keynes: Open University Press.
Koch, T. 1994: Establishing rigour in qualitative research: the decision trail. Journal of Advanced Nursing 19, 976-86.

Meyer, J. 1993: New paradigm research in practice: the trials and tribulations of action research. Journal of Advanced Nursing 18 (7), 1066-72.

Meyer, J. and Batehup, L. 1997: Action research in health-care practice: nature, present concerns and future possibilities. NT Research 2, 175-84.

Meyer, J. and Bridges, J. 1998: An action research study into the organisation of care for older people in the A\&E Department. London: City University.

Meyer, J., Cotter, A. and Roberts, S. 1999: Weaving a cloth of width and quality: an action research study at the primary and secondary care interface to establish innovative ways of involving older users and carers in the assessment of individual health and social continuing care needs. Funded by $\mathrm{DoH}$ Building Partnerships for Success: Community Care Development Programme. London: City University.

Murphy, E. 2001: Micro-level qualitative research. In Fullup, N., Allen, P., Clarke, A. and Black, N. (editors), Studying the organisation and delivery of Health Services. London: Routledge, 40-55.

NHSE. 1997: $R \& D$ in primary health care (The Hant report). London: Department of Health.

Polanyi, M. 1962: Personal knowledge: towards a post-critical philosophy. London: Routledge \& Kegan Paul.

Reed, J. and Proctor, S. 1995: Practitioner research in health care. The inside story. London: Chapman \& Hall.

Rolfe, G. 1998: Expanding nursing knowledge. Understanding and researching your own practice. Oxford: Butterworth Heinemann.

Ryle, G. 1963: The concept of mind. Harmondsworth: Penguin.

Sackett, D.L., Richardson, W.S., Rosenberg, W. and Haynes, R.B. 1997: Evidence-based medicine. How to practice and teach EBM. Edinburgh: Churchill Livingstone.

Schon, D. 1983: The reflective practitioner. London: Temple Smith.

Silverman, D. 1993: Interpreting qualitative data. London: Sage.

Simons, H. 1971: Innovation and the case study of schools. Cambridge Journal of Education 3, 120-2.

Somekh, B. 1994: Inhabiting each other's castles: towards knowledge and mutual growth through collaboration. Educational Action Research 2, 357-81.

Susman, G.I. and Evered, R.D. 1978: An assessment of the scientific merits of action research. Administrative Science Quarterly Dec 23, 582-603.

Walshe, K., Ham, C. and Appleby, J. 1995: Given in evidence. Health Service Journal 29 June, 28-29.

Waterman, H., Dickson, R., de Koning, K. and Lewis, S. 2001: Action research: a systematic review and guidance for assessment. HTA R\&D Programme.

Winter, R. and Munn-Giddings, C. 2001: A handbookfor action research in health and social care. London: Routledge.

Wood, M. and Ferlie, E. 2000: The Role of the Investigator in the Translation of NHS R\&D Findings into Practice. Final Report. NHS Executive London, R\&D Programme, December. 